\title{
Earthquake volume, fault plane area, seismic energy, strain, deformation and related quantities
}

\author{
Markus BATH - Sewerya J. DUdA
}

Ricevuto il 25 Gennaio 1964

Summary. - An effort is marle to improve Benioff's methor for investigation of strain release in aftershock sequences. The improvement may be summarized as follows:

1. Farthquake volume increases with magnitude, instead of being constant. A relation is given, relating volume to magnitude.

2. A revised energy-magnitude formula is used.

3. The seismic gain ratio, i. e. the ratio between seismic energy and elastic strain energy, probably increases with magnitude, instead of being constant. Likewise, the ratio of fault plane area of the main shock to the vertical section through the aftershock volume increases with magnitude.

4. The seismic energy density, the elastic strain energs density as well as strain are independent of magnitude.

5. The deformation. i. e. the total strain in the aftershock zone, increases with magnitude at the same rate as seismic energy and volume do.

As a consequence of these improvements some earlier published strain release characteristics are reconstructed, this time as deformation characte. ristics instearl.

Riassunto. - Gli Autori si sono sforzati di modificare il metorlo di Benioff, sullo studio delle tensioni liberate in una serie di repliche di terremoti. Le morlifiche possono essere riassunte come segue:

1. II "volume" del terremoto aumenta con la marnitudo, invece di rimanere costante. È data la relazione che lega il "volume " alla magnitudo.

2. Viene usata dagli AA. una formula corretta energia-magnitudo.

3. Il rapporto sismico ottenuto, cioc il rapporto fra l'energia sismica e l'energia delle tensioni elastiche, aumenta, probahilmente, con la magnitudo, invece di essere costante; come pure avviene per il rapporto fra larea del piano di faglia della scossa principale e la sezione verticale tracciata lungo il "volume" della replica. 
4. La densita dell'energia sismica, e quella dell'energia delle tensioni elastiche come sforza, sono indipendenti dalla magnitudo.

5. La deformazione, cioe la tensione totale nella zona della replica del terremoto aumenta con la magnitudo nella stessa misura con cui aumentano l'energia sismica e il "volume".

Come conseguenza di queste modifiche, alcune recentemente pubblicate, sono state ricostruite le curve caratteristiche delle tensioni liberate, invece. delle curve caratteristiche delle deformazioni, fin qui usate.

\section{INTRODUCTION.}

Benioff initiated strain release studies around 1950 . Since that time the same method as originally given by Benioff (1951), has been used by all who have worked in this field, including ourselves. In the original method, strain is proportional to the square root of the released seismic energy. The volume of every aftershock was considered constant and equal to the total volume of the aftershock zone. The fraction of elastic energy converted into seismic energy was also assumed constant. Moreover, an older energy-magnitude formula has been used for consistency reasons, although newer and better formulas have been developed in the meantime. In the present paper an effort is described to improve Benioff's method, especially in the directions mentioned.

\section{Notation.}

We shall be using the following notation throughout the present paper:

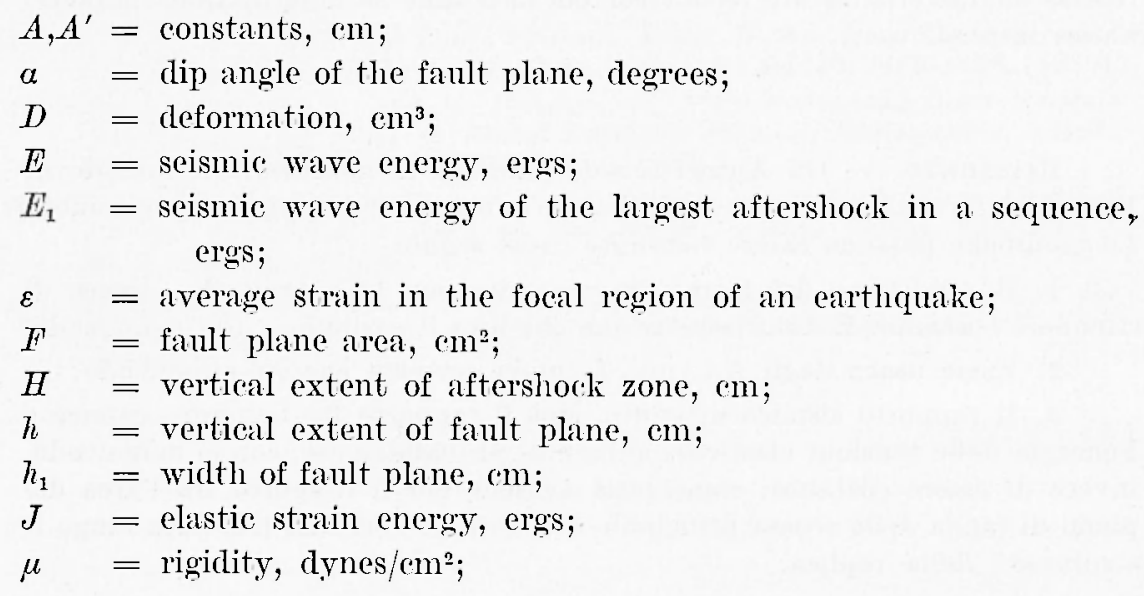




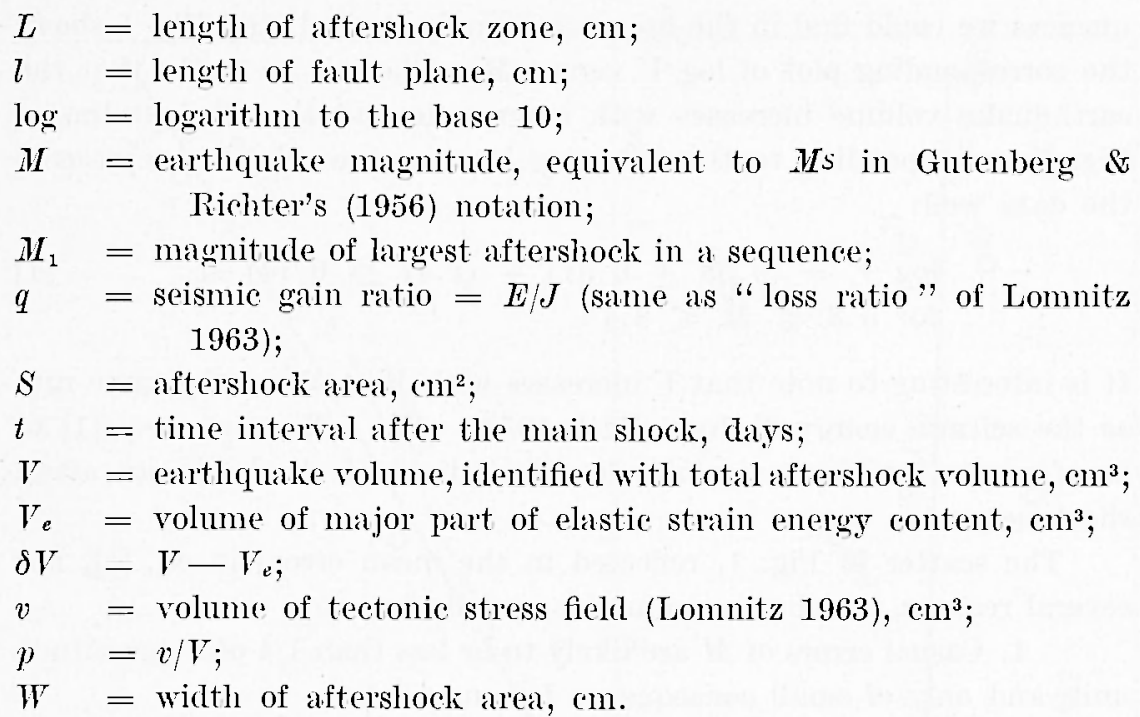

\section{EARTHQUATE VOLUME AXD MaGNitUde.}

The earthquake volume is not accessible for direct measurements and it is natural that slightly different definitions have appeared in the literature. Bullen $(1953,1955)$ identifies the earthquake volume with the strained region, in which the material is near breaking-point prior to an earthquake. Bullen (1963) uses the term focal region to denote the volume from which the major part of the energy is issued. Tsuboi (1956) also defines the earthquake volume as the one where the seismic energy was stored before the earthquake. Gzovsky (1962) calls "the space around the fracture in which a redistribution of elastic deformation energy is taking place" the earthquake focus. Benioff (1950) defined the original strain zone as the total volume of the aftershocks. Benioff (1962) estimated on the basis of some results by Byerly and DeNoyer (1958) that the strain is confined to a very narrow zone around the fault. However, inferences from geodetic measurements may be of limited applicability because of their necessary limitation to the earth's surface. Unfortunately, there are no measurements available which permit a collocation of the ideas of the two Benioff papers mentioned.

We define earthquake volume as the volume of major energy content and assume this to be identical with Benioff's (1955) original strain zone. Table I summarizes all pertinent information on aftershock se- 
quences we could find in the literature, partly revised, and Fig. 1 shows the corresponding plot of $\log V$ versus $M$. There is no doubt that the earthquake volume increases with magnitude and the straight line in Fig. 1, corresponding to the following least-square solution, represents the data well:

$$
\begin{aligned}
& \log V=(9.58 \pm 0.51)+(1.47 \pm 0.14) M \\
& \text { for } 5.3 \leqslant M \leqslant 8.7 .
\end{aligned}
$$

It is interesting to note that $V$ increases with $M$ at about the same rate as the seismic energy $E$ does (Bath 1958). We will assume eq. [1] to be of general validity, e.g. also for the individual shocks in an aftershock sequence.

The scatter in Fig. 1, reflected in the mean errors in eq. [1], has several reasons, which we summarize as follows:

1. Casual errors of $M$ are likely to be less than $1 / \pm$ of a magnitude unit, and only of small consequence for our relation.

2. Errors of $\boldsymbol{V}$ may be of greater consequence, because of uncertainties in length, width and depth of aftershock zones. However, as we are naturally only concerned with orders of magnitude of the volume, these uncertainties are also only of minor importance. In the sequences used, there are some variations in the magnitude range and time interval considered, but these have practically no influence on the result. Recent observations of free oscillations of the earth and of surface waves have permitted an estimate of the fault length (Benioff, Press and Smith 1961; Press, Ben-1Lenahem and Toksoz 1961; BenMenahem and Toksoz 1962), indieating that the length of the aftershock area exceeds the original fault length only by some 10 percent, agreeing with independent data for Kern County 1952, a systematic error of no consequence here. Information from geological expeditions is also in good accord with our assumption. The percentage error of the rertical dimension is somewhat greater than for the other two.

3. Systematic variation of $\mathrm{V}$ may exist in comparing different earthquake regions. Unfortunately, very little information is available on this point, except for a few hints. Duda (1963) found indication for a more brittle rheological behaviour in Chile than in the Aleutian Islands or Kamchatka. The comparatively low volume found for the Kern County earthquake may be explained by a reduced shear strength because of many fractures and minor faults in the area (Benioff 1955) or more specifically by the intervention of the Edison fault into the activity on the White Wolf fault (Duda and Bath 1963). 
EARTHQUAKE VOLUME, FAULT PLANE AREA, SEISMIC ENERGY, ETC. 357

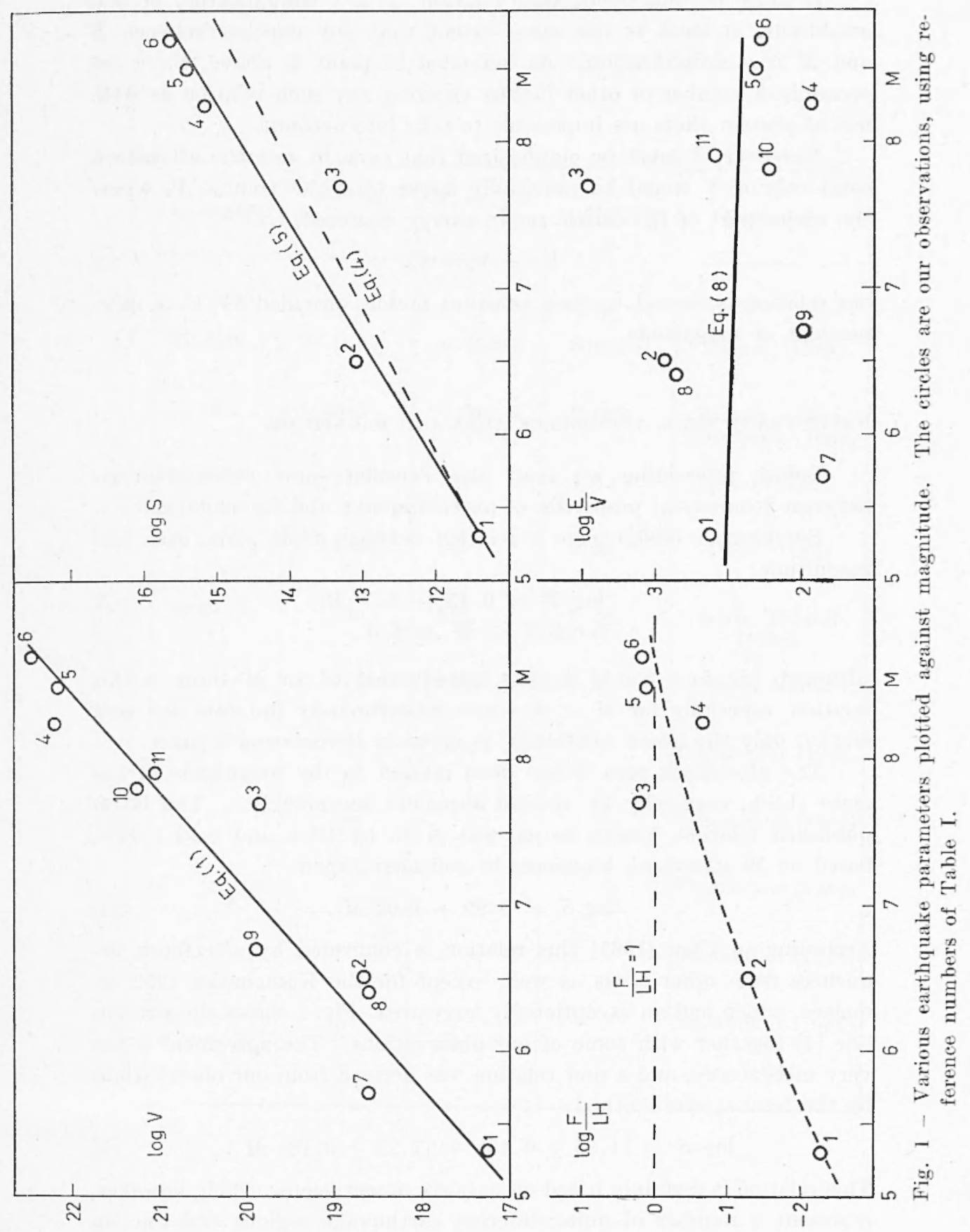


It must be understood that relation $[1]$ is a simplifieation of real ronditions, at least to the same extrent that any relation between $E$ and $M$ is a simplification. As indicated in point 3 . above, there are certainly a number of of her factors entering any such relation as well, but at present these are impossible to take into areount.

Horeover, it must be amphasized that even in rase the aftershock total volume $V$ would be essentially latger than the volume $V_{e}$ where the major part of the elastie strain energy is stored, i. e.

$$
V=V_{c}-\delta V
$$

our relation is correct $u$ to to a constant factor, provided $\delta V / V_{e}$ is indeperndent of magniturle.

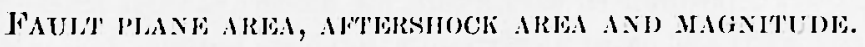

Before procereding wo shall also ronsider some other relations between geomedrial properties of an earthquake and its magnitude.

Borckhemer (1962) gave a relation between fault plane area and magnitude:

$$
\begin{aligned}
& \log H=0.15+1.7 M \\
& \text { for } 5.5 \leqslant M \leqslant 8.0 .
\end{aligned}
$$

Although his data would suggest introduction of an $3 L^{3}$-term in this relation, especially for $M<6$, where unfortumately the data are very scanty, only the linear pelation [3] is griven in Berckhemer's paper.

The aftershorek area is has been rolated to the magniturle of the main shock, especially by sevemal Japanese seismologrists. The latest publisherl relation, known to us, was given by Utsu and Soki (1955), baserd on 39 aftershork secfuences in and near Japan:

$$
\log S=\tilde{5} .99+1.02 M .
$$

Aceording to Utsu (1961) this relation is confirmed by aftershock se(quences from other areas as well, except for the Kamchatka 1952 sequence, which had an exeeptionally large area. Fig. 1 shows the straight line [-1] together with some of our observations. The agreement is not very satisfactory, and a new relation was derived from onr observations by the least-scuuare method:

$$
\log N=(1.95 \pm 0.43)+(1.21 \pm 0.18) M .
$$

This relation is certainly based on only six observations, which, however, represent a number of quite different earthouake regions and line up) 
Table I - Data for earthiquakes USEd IN tuIs stedr.

\begin{tabular}{|c|c|c|c|c|c|c|c|c|c|c|c|c|c|c|c|c|c|}
\hline No & Date & $\begin{array}{l}\text { Origin time } \\
\text { GaIT }\end{array}$ & Lat. & Long. & Region & .11 & $\begin{array}{l}E, \text { eq. }[7] \\
10^{20} \mathrm{ergss}\end{array}$ & $1,10^{20} \mathrm{~cm}^{3}$ & $E / \mathrm{V}, \mathrm{erg} / \mathrm{cm}^{3}$ & $S^{\prime}, 10^{12} \mathrm{~cm}^{2}$ &.$H_{1}$ & $\log \left(E / E_{1}\right)$ & $\alpha$, degrees & $\begin{array}{c}L \times I I \\
I\left(11^{12} \cdot \mathrm{cm}^{2}\right.\end{array}$ & $\begin{array}{l}F \cdot(a|\cdot| 3 \mid \\
\mid 0^{2}=2 \cdot 11^{2}\end{array}$ & F. LIII & Referemere \\
\hline 1 & 22 Mar. 1957 & 194421.0 & $37.7 \mathrm{~N}$ & $122.5 \mathrm{~W}$ & $\therefore$ Francisco & 5.3 & $0.7+1$ & 0.00175 & +23 & 0.25 & 4.4 & 1.30 & $77.6-5 ! 9.7$ & 0.633 & 0.00288 & 0.005 & Thower (1959) \\
\hline 2 & + Dec, 1948 & $1543 \quad 16.7$ & $33.9 \mathrm{~N}$ & $116.4 W$ & Desert lot springs & 6.5 & 39.8 & 0.0460 & 865 & 13 & 4.9 & 2.30 & $\geqslant 66$ & 6.3 & 0.316 & 0.050 & $\begin{array}{l}\text { Richter. Allen. } \\
\text { Sortlquist (1958) }\end{array}$ \\
\hline 3 & 21 July, 1952 & $11 \quad 5214.3$ & $35.0 \times$ & $119.0 \mathrm{~W}$ & Kern County & 7.7 & 2140 & 0.730 & 2930 & 21 & 6.4 & 1.87 & 601.66 & 21 & 34.7 & 1.65 & Beniofl' (195.5) \\
\hline 4 & 9 Mrar, $195 \bar{t}$ & $1422 \quad 27.5$ & $51.3 x$ & $175.8 \mathrm{~W}$ & Aleutian Islants & $81 / 4$ & 13200 & 154 & 86 & 1540 & 7.3 & $1.3 \bar{i}$ & 86 & 1330 & 299 & 11.2.2. & Dudal (19192) \\
\hline 5 & 4 Nov, 1952 & 165826 & $52.8 \times$ & $159.5 \mathrm{E}$ & Kanchatka & 8.5 & 30200 & 148 & 204 & $2+70$ & $71 / 4$ & 1.80 & $79-89$ & 620 & $79+$ & 1.28 & $\begin{array}{l}\text { Bath, Beniont } \\
(1958)\end{array}$ \\
\hline it & $22 \mathrm{May}, 1960$ & 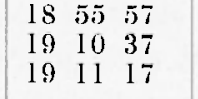 & $38-39.5 \mathrm{~s}$ & $73.5-74.5 \mathrm{~W}$ & Chile & 8.7 & 58900 & 303 & 194 & 4030 & 7.5 & 1.73 & - & 1130 & $17+0$ & 1.54 & Budla (19(63) \\
\hline$i$ & $10 \mathrm{Apr}, 195 \mathrm{~s}$ & $10 \quad 5531$ & $51.5 x$ & $99 \mathrm{l}:$ & Outer Mongolia & 5.7 & 2.82 & $(0.04)$ & 71 & - & 一 & - & - & & & & P'shemikor (1962) \\
\hline 8 & (5) Feb, $195 \overline{7}$ & 203455 & $50 \mathrm{X}$ & $105.5 \mathrm{~L}$ & Lalke Baikal & (i. 4 & 28.8 & $(0.04)$ & 720 & -... & - & $\cdots$ & - & - & - & - & Pshemikos (1962) \\
\hline 9 & 29 Aug. 1959 & $\begin{array}{lll}17 & 03 \quad 10\end{array}$ & $52 x$ & $106.5 \mathrm{E}$ & Lake Baikal & 6.7 & 77.6 & 0.79 & 98 & $\cdots$ & - & - & - & - & & & 1'shemuikor (196(2) \\
\hline 10 & + Dec, $195 \overline{7}$ & $03 \quad 3745$ & $45.5 \times$ & $99.5 \mathrm{E}$ & Outer Mongolia & 7.8 & 2950 & 18 & 164 & - & 6.5 & 1.87 & - & - & $\cdots$ & & Pshennikes (1962) \\
\hline 11 & 27.June, 1957 & $\begin{array}{llll}00 & 09 & 28\end{array}$ & $56.5 \times$ & $116 \mathrm{l}:$ & NE Lake Baikal & 7.9 & +170 & 11 & 379 & -- & - & -.. & - & - & - & - & Pshemnikor (1!162) \\
\hline
\end{tabular}


remarkably well on a straight line, again with exception for Kern County 1952, which is low.

From the geometry of Fig. 2 , showing the fault plane of the main shock inside the total aftershock volume, in the shape of a parallelopiped, we have immediately the following relations:

$$
Y=L W H ; \quad S=L W ; \quad F=h_{1} ; \quad h_{1}=h / \sin \alpha \quad[6]
$$

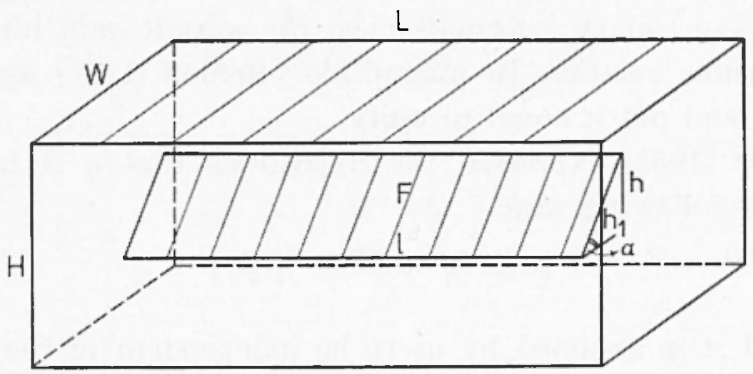

Fig. 2 - Schematical picture of fault plane inside aftershock volume.

For the cases with available information on $a$ (Table I), it is obvious that $\sin a \geqslant 0.85$, and therefore we can put $h_{1}$ approximately equal to 7 . For obvious reasons, $F / L H \leqslant 1$. This latio is plotted against magnitude in Fig. 1 (see also Table I). There is evidently some indimation of an increase of $F / L H$ with $M$, approarching unity for the largest shocks, as shown by the dotted rurve in Fig. 1 .

\section{FLASTIC STRAIX ENERGY AND SEISHIC ENERGY.}

Combining eq. [1] with Bath's (1958) energy-magnitude formula:

$$
\log E=(12.24 \pm 1.35)+(1.44 \pm 0.20) M
$$

we find that

$$
\log (E / T)=(2.66 \pm 1.86)-(0.03 \pm 0.34) M
$$

This means that the seismic energy density, i.e. the seismic energy per unit rolume, is independent of the magnitude. Fig. 1 shows the straight line [8] together with our observations. Similar results have been expressed by Pshemnikor (1962).

From the values in Table I we find that for circum-Pacific earthquakes, cases 1-6, the average value of $\log \left(E / E_{1}\right)=1.73 \pm 0.29$, corresponding to an arerage of $M-m_{i}=1.2 \pm 0.2$, an excellent con- 
firmation of the so-called Bath's law (Richter 1958, p. 69). This agrees with No. 10 (Outer Mongolia).

The source from which earthquakes derive their energy, i. e. the potential energy within the earth, is not accessible to direct measurements. The potential energy consists mainly of the elastic strain energy, even if some other kinds of potential energy, due to the state of the material, cannot be excluded, especially at greater depth (Benioff 1963). So far we have had no information on the seismic gain ratio $q=E / J$ and its possible relation to magnitude. Benioff (1951) assumed $q$ to be constant and put it equal to unity.

Lomnitz (1963) expressed the hypothesis that $q$ is related to $F$ and $v$ in the following way:

$$
q=A^{\prime} F / v=A F / V
$$

with $A^{\prime}$ and $A^{\prime} / p$ assumed by us to be independent of the magnitude. Even if the expression [9] seems to be reasonable, we have to remember that it is nothing more than a hypothesis. Then, $q$ would increase with magnitude at the same rate as $F / V$ (Table II). Assuming that $q$ has reached its maximum value, i. e. unity, for the largest shocks (here taken as $M=8.7$ ), as inferred from our result concerning magnitude variation of $F / L H$, we get the maximum value of $A=1.35 \times 10^{7} \mathrm{~cm}$. With this value of $A$ together with eqs [9], [3] and [1] we find that

$$
\log q=(-2.00 \pm 0.51)+(0.23 \pm 0.14) M \text {. }
$$

We see from Table II that about seven times more of the elastic strain energy is converted into seismic energy for an earthquake of magnitude 8.7 as for one of magnitude 5.0.

From the definition of $q$ and eq. [9] we get

$$
\log J=\log E-\log A-\log F+\log V .
$$

Inserting eqs. [1], [3], [7] and $A=1.35 \times 10^{7} \mathrm{~cm}$, we find that

$$
\log J=(14.24 \pm 1.86)+(1.21 \pm 0.34) M .
$$

Under the same conditions we immediately derive the following expression for the elastic strain energy density:

$$
\log (J / V)=(4.66 \pm 1.35)-(0.26 \pm 0.20) M .
$$

There is no significant variation of $J / V$ with $M$, just as the case is with $E / V$, eq. [8]. 


\begin{tabular}{|c|c|c|c|c|c|c|c|c|c|}
\hline 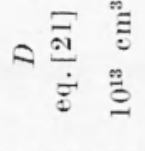 & $\dddot{\leftrightarrow}$ & $\stackrel{\varphi}{-}$ & $\stackrel{0}{\infty}$ & $\stackrel{f}{\circ}$ & 号 & 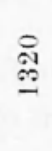 & $\stackrel{\theta}{=}$ & 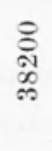 & $\underset{\substack{\infty \\
\stackrel{+}{+}}}{ }$ \\
\hline$\omega \stackrel{g}{\Xi} \stackrel{0}{\dot{\theta}}$ & $\begin{array}{l}\infty \\
\stackrel{\sim}{9} \\
\infty\end{array}$ & هి & $\stackrel{t}{\ddot{0}}$ & $=$ & $\begin{array}{l}\mathscr{8} \\
\stackrel{8}{0}\end{array}$ & $\begin{array}{l}\overrightarrow{0} \\
\therefore\end{array}$ & $\begin{array}{l}\mathscr{0} \\
\text { o. }\end{array}$ & $\begin{array}{c}\mathscr{Q} \\
\text { ai }\end{array}$ & $\begin{array}{l}\infty \\
\infty \\
\infty \\
\text { d }\end{array}$ \\
\hline$\omega \begin{array}{l}\bar{z} \\
\dot{\vec{g}}\end{array}$ & $\begin{array}{l}\stackrel{i}{\infty} \\
\infty\end{array}$ & is & †े & $\begin{array}{l}10 \\
10\end{array}$ & $\stackrel{\infty}{\infty}$ & $\stackrel{\infty}{\dddot{2}}$ & $\begin{array}{l}0 \\
0 \\
0\end{array}$ & $\begin{array}{l}\stackrel{\leftrightarrow}{\circ} \\
\dot{\leftrightarrow}\end{array}$ & $\begin{array}{l}\infty \\
\infty \\
\text { o }\end{array}$ \\
\hline 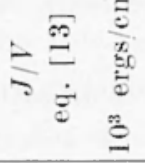 & $\begin{array}{l}\text { जे } \\
\text { ai }\end{array}$ & $\stackrel{8}{-}$ & $\stackrel{\mathscr{̣}}{\stackrel{\leftrightarrow}{\prime}}$ & $\stackrel{8}{0}$ & $\begin{array}{l}0 \\
\dot{0} \\
\dot{0}\end{array}$ & 官 & $\begin{array}{l}\infty \\
\stackrel{0}{0} \\
\stackrel{0}{0}\end{array}$ & 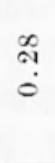 & $\stackrel{\leftrightarrow}{\stackrel{9}{0}}$ \\
\hline 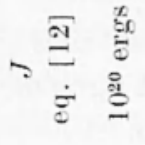 & $\stackrel{10}{5}$ & $\begin{array}{l}10 \\
\infty \\
\stackrel{0}{1}\end{array}$ & $\frac{\varphi}{\infty}$ & $\stackrel{\mathrm{N}}{\stackrel{\mathrm{N}}{-}}$ & $\stackrel{\infty}{10}$ & 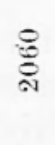 & 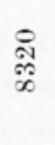 & $\begin{array}{l}\stackrel{0}{0} \\
\text { 10. } \\
\text { ஸी }\end{array}$ & $\begin{array}{l}8 \\
16 \\
0 \\
10\end{array}$ \\
\hline$\Leftrightarrow=\begin{array}{ll}\bar{E} & \text { bे } \\
\dot{\bar{\theta}} & \stackrel{b}{0}\end{array}$ & 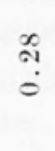 & $\stackrel{10}{\stackrel{9}{-}}$ & 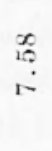 & 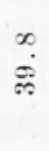 & : & $\stackrel{\mathscr{g}}{\stackrel{g}{O}}$ & 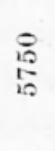 & $\begin{array}{l}\stackrel{\text { }}{\text { }} \\
\text { م) }\end{array}$ & 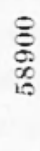 \\
\hline$=\frac{\overline{9}}{\dot{0}}$ & $\frac{\mathcal{N}}{\stackrel{ \pm}{ \pm}}$ & $\frac{\vec{\infty}}{\stackrel{0}{0}}$ & $\begin{array}{l}\stackrel{P}{+} \\
\stackrel{0}{0} \\
\text {. }\end{array}$ & $\frac{\dddot{m}}{\dddot{0}}$ & $\stackrel{\infty}{\stackrel{\infty}{\dagger}}$ & $\begin{array}{l}\stackrel{0}{\tilde{\vartheta}} \\
\stackrel{i}{0} \\
\dot{0}\end{array}$ & $\begin{array}{l}\stackrel{0}{0} \\
\dot{0} \\
\dot{0}\end{array}$ & $\begin{array}{l}\stackrel{\vartheta}{\hat{S}} \\
\dot{0} \\
\dot{0}\end{array}$ & $\stackrel{g}{g}$ \\
\hline 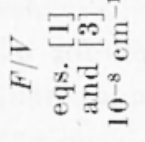 & $\stackrel{10}{0}$ & r. & 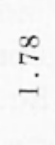 & $\begin{array}{l}\stackrel{\lambda}{\curvearrowright} \\
\text { م. }\end{array}$ & $\begin{array}{l}\text { Oे } \\
\text { ه }\end{array}$ & $\begin{array}{l}\vec{D} . \\
\oplus \dot{0}\end{array}$ & $\stackrel{\oplus}{\because}$ & $\begin{array}{l}\infty \\
\stackrel{0}{0} \\
\dot{0}\end{array}$ & 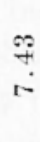 \\
\hline$=$ & $\stackrel{9}{10}$ & 10 & $\dot{0}$ & $\stackrel{10}{0}$ & $\stackrel{8}{\therefore}$ & $\stackrel{9}{\therefore}$ & $\stackrel{\theta}{\infty}$ & $\stackrel{\leftrightarrow}{\infty}$ & $\because$ \\
\hline
\end{tabular}


STRAIX RELEASF AXD DEFORMATION CHARACTERISTICS.

With reference to Bath and Beniof: (1958) we have the following formula for calculation of the average strain $\varepsilon$ :

$$
E-1, q \mu \varepsilon^{2} I
$$

The strain is in this formula composed of a distortional and a dilatational part, which cannot be separated from each other. Also, the volumes of distortional and dilatational strain energy storage have to be assumed equal.

In the light of the results rescriber earlier in this paper, we suggest the following improvements of Benioff's (1951) original method in the application of eq. [14]:

1) $V$ will vary with $M$ according to $[1]$ instead of being assumed constant;

2) $q$ is assumed to vary with $M$ according to [9], as an alternative to the still plausible assumption of constant $q-1$ according to Beniofl (1951);

3) $E$ varies with $M$ according to [7], being the most reliable energy-magnitude formula so far produced, in excellent agreement with an independent result by Gutenbere and Richter (1956).

The rigidity $\mu$ will still be assumed constant $=6 \times 10^{11}$ dynes $/ \mathrm{em}^{2}$, valid for the upper part of the earth where the arthquakes considered took place. However, there are some indications that $\mu$ depends on the stress state of the material (Duda 1962).

Solving eq. [1t] for $\varepsilon$ and considering only the positive root, which may be approximately correct as long as we consider only one earthquake area at a time, we have

$$
\varepsilon=\left(\frac{2 E}{q \mu V}\right)^{1 / 2} .
$$

We consider two cases, depending upon the expression for $q$ chosen. 1) $q=A \mathrm{~F} / \mathrm{T}$, i. e. eq. [9]. Eq. [15] then becomes

$$
\varepsilon=\left(\frac{2 E}{A \mu F}\right)^{1 / 2} .
$$

Applying edgs $[\bar{\tau}]$ and $[3]$ and putting $A=1.35 \times 10^{7}$ ('m, we obtain that

$$
\log \varepsilon=-(3.41 \pm 0.68)-(0.13 \pm 0.10) M .
$$


2) $q=1$. In this cuse, [15] becomes

$$
\varepsilon=\left(\frac{2 E}{\mu V}\right)^{1 / 2}
$$

Inserting eqs [1] and [7], we find that

$$
\log \varepsilon=-(+.41 \pm 0.93)-(0.015 \pm 0.17) M .
$$

The resulting eqs [17] and [19] agree in the sense that the strain has no significant variation with magniturle. See Table II.

This result may seem surprising at first sight. However, it is in better accord with general inferences from rock behaviour under stress than that strain should increase lapidly with magnitude. The essential difference between large and small shocks is not to be found in the strain release but in the volume within which a release takes place at the same time. The rock can store a certain amount of strain before it breaks. If strain were magnitude-dependent this would mean that each rock should be able to store strain corresponding to a certain minimum earthquake magnitude. It is then a justified question why in seismic areas not only shocks above a certain magnitude exist, but also a far greater number of smaller shocks. Our result of constant strain but magnitudedependent volume seems to meet these problems.

In order to study creep phenomena in aftershock sequences, Benioff (1951) initiated the construction of strain release characteristics. Under the term strain, we understand deformation per unit volume, by virtue of the fact that deformation in the neighbourhood of any point can always be expressed as the resultant of simple extensions (called prin(ipal extensions) in three mutually perpendicular directions (called the principal axes of strain). See Bullen (1963, p. 17). We still consider a strain characteristic as valuable in rescribing the behaviour of the rock under stress, but we are now unable to construct any such curve becaluse of the following facts:

1) As strain is independent of magnitude, we should need to know all aftershocks, especially the large number of small ones, to be able to construct a reliable curve. However, such information is naturally not available.

2) Considering strain, we are only concerned with one particular unit volume. It would be incorrect to add strains from quite different volumes, as would be the case if strains of many small aftershocks in different parts of a large aftershock region were added.

For these reasons, we have to refrain from tracing any strain release characteristies. On the other hand, deformation characteristies, re- 
ferring to the whole aftershock volume can be traced because of the theorem mentioned (Bullen 1963, p. 17) and because neither of the objections above is applicable in this case. In addition, as focal mechanisms are very similar or closely related within one and the same earthquake area (Bath 1952), the principal axes of strain are approximately conserved within such an area and it will be justified to add deformations from different parts of the same area. The deformation characteristic gives a true picture of the real happenings in the aftershork zone and has an obvious interest from the tectonophysical point of view. Of course, under Benioff's (1951) assumptions the strain and deformation characteristics had the same shape, differing only by a constant factor.

Using eq. 18], i. e. assuming $q=1$, we have

$$
D=\varepsilon V=\left(\frac{2 E V}{\mu}\right)^{\prime \prime}
$$

which in combination with eqs [1] and [7] becomes

$$
\log D=(5.17 \pm 0.93)+(1.46 \pm 0.17) M
$$

$E, V$ and $D$ all increase with $M$ at about the same rate.

Using eq. [21] on two aftershock sequences for which the material laas been published earlier, i. e. Aleutian Islands 1957 (Duda 1962) and Chile 1960 (Duda 1963), we have constructed the deformation characteristir's shown in Fig. 3.

The accumulated deformation in the aftershock zones an be represented analytically as follows:

Aleutian Islands 1957:

1st branch $0.031 \leqslant t \leqslant 1.36 \quad D=(1.48+0.96 \log t) \times 10^{16}$

2nd branch $1.36 \leqslant t \leqslant 6.4 \quad D=(1.05+4.19 \log t) \times 10^{16} \quad$

3rd branch $6.4 \leqslant t \leqslant 39 \quad D=(1.95+3.07 \log t) \times 10^{10}$

th branch $39 \leqslant t \leqslant 1266 \quad D:=(3.67+1.99 \log t) \times 10^{16}$

Chile 1960:

$\left.\begin{array}{l}\text { 1st branch } 0.122 \leqslant t \leqslant 7.90 \quad J)=(0.41+0.42 \log t) \times 10^{16} \\ \text { 2nd branch } 7.90 \leqslant t \leqslant 952 \\ \qquad D=\left[0.79+5.03\left(1-e^{\left.-0.12(t-7.9)^{1 / 2}\right)}\right] \times 10^{16} .\right.\end{array}\right\}$

The end-4th branches of the Aleutian Islands deformation characteristic are only to be understood as straight-line approximations for an exponential curve, extending over the entire interval $1.36 \leqslant t \leqslant 1266$, i. e. corresponding to the second branch for the Chile 1960 characteristic. Our improved methods have had the consequence that the earlier pub- 


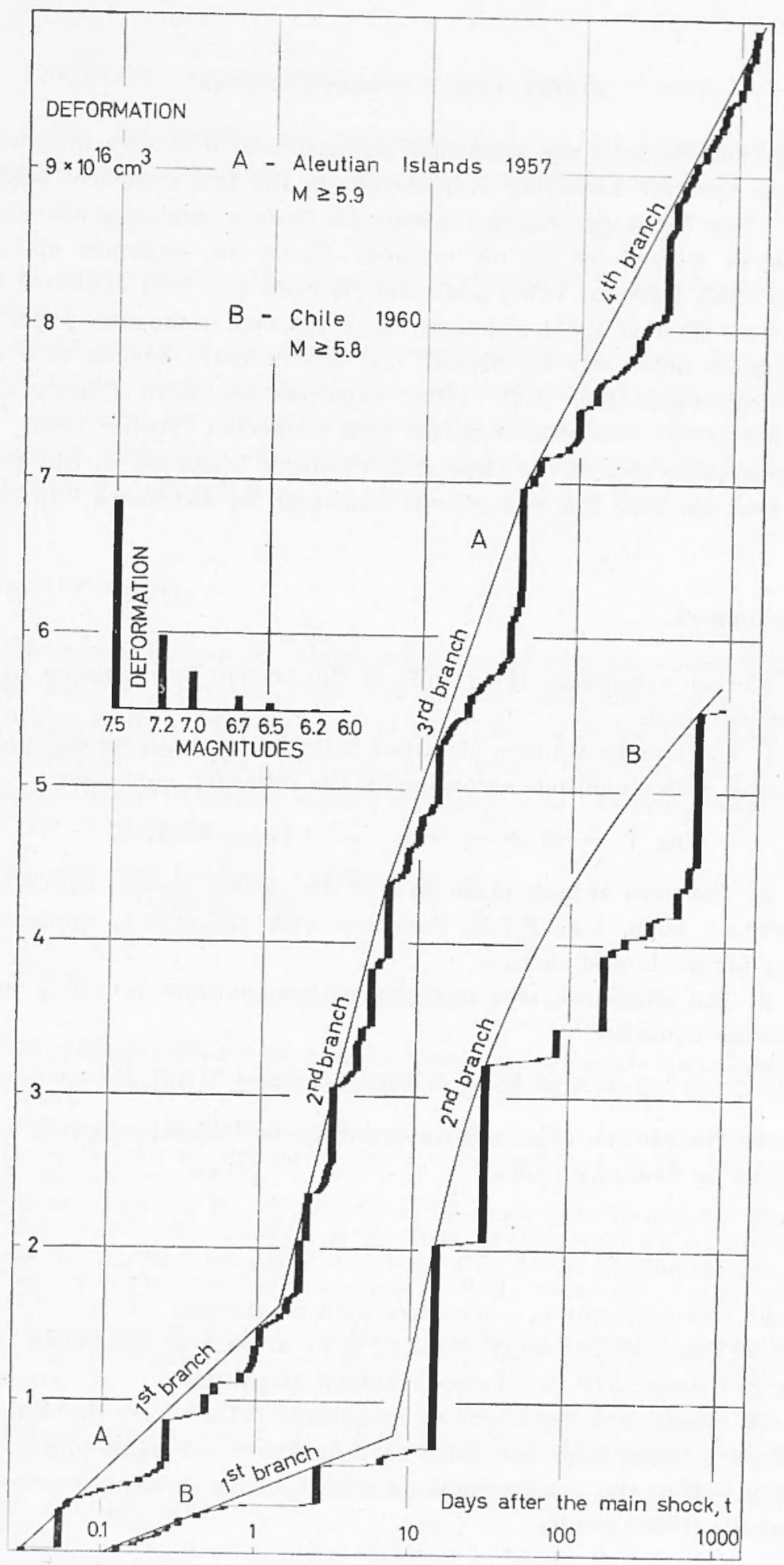

Fig. 3 - Deformation characteristics for the Aleutian Islands 1957 and Chile 1960 aftershock sequences. 
lished characteristics are somewhat changed, and it is very interesting to note that the behaviour is analogous in the two sequences studied here. This behaviour was also eviclent for quite a number of aftershock sequences studied by the old method. Thus, the sequences of Long Beach 1933, Imperial Valley 1940 and Hawke's Bay 1931 exhibited this behaviour (Benioff 1951), also some others reported in the same paper but interpreted differently by Benioff, i. e. Manix 1947, Nevada 1932 and less clear Signal Hill 1933. Other examples are Kern County 1952 (Benioff 1955) and San Francisco 1957 sequences (Tocher 1959). It remains to be seen if the improved technique presented in this paper will bear out that this is a general behaviour for aftershock sequences.

\section{Conclusions.}

We can summarize the results of the present investigation in the following points.

1. Earthquake volume, identified with the total aftershock volume, increases with magnitude according to the following equation:

$$
\log V=(9.58 \pm 0.51)+(1.47 \pm 0.14) M .
$$

2. The ratio of fault plane area to the vertical section through the aftershock zone, i.e. $F / L H$, increases with magnitude, approaching unity for the largest shocks.

3. The aftershock area increases with magnitude according to the following equation:

$$
\log S=(4.95 \pm 0.43)+(1.21 \pm 0.18) M .
$$

4. The seismic gain ratio is expressed as follows, adopting a suggestion by Iomnitz (1963):

$$
q=\frac{E}{J}=A \frac{F}{V}
$$

Under this assumption, $q$ increases with magnitude.

5. The seismic energy density, $E / V$, as well as the elastic strain energy density, $J / V$, are independent of magnitude.

6. Strain is independent of magnitude. Therefore, the main difference between large and small earthquakes is not to be found in the strain but in the total volumes involved. This is in agreement with Tsuboi's (1956) results. 
7. The deformation, i.e. the total strain in the aftershock zone, increases with magnitude according to the following formula:

$$
\log D=(5.17 \pm 0.93)+(1.46 \pm 0.17) \mu
$$

i. e. at almost exactly the same rate as the seismic energy $E$ or the volume $T$.

8. By means of the improved method given in this paper, some earlier strain release characteristics (Aleutian Islands 1957 and Chile 1960 sequences) are reconstructed, now as deformation characteristics. It appears likely that most aftershock sequences exhibit similar deformation-time characteristics.

\section{ACKNOWLEDGMENT.}

The research reported in this paper was carried ont at the SeismoIogical Institute, Uppsala, with the support and sponsorship of the Cambridge Research Laboratories of the Office of Aerospace Research, United States Air Force, through its European Office, as part of the Advanced Research Project Agency's project Vela Uniform, under contract $A F \quad 61(052)-588$.

Seismological Institute, Uppsala, Sweden January, 1964

\section{REFERENCES}

BAtrI M., Initial Motion of the First Longitudinal Earthquake Wave Recorded at Pasadena and IIuancayo. "Bull. Seism. Soc. Amer.", 42, 175-195, $(1952)$.

- The Energies of Seismic Body Waves and Surface Waves. "Contributions in Geophysies in Honour of Beno Gutenberg", 1, 1-16, Pergamon Press, London, (1958).

BAtr M. and BeniofF H., The Affershock Sequence of the Kamchatha Earthquake of November 4, 1952. "Bull. Seism. Soc. Amer.", 48, 1-15, (1958).

Beniofr H., Earthquales and Rock Creep, Part I: Creep Characteristics of Rocks and the Origin of Aflershocks. "Bull. Seism. Soc. Amer.", 41, $31-62,(1951)$.

- Mechanism and Strain Characteristics of the White Wolf Fault as indicated by the Aftershock Sequence. "Calif. Dept. Nat. Resources, Division of Íines, Bull.". 171, Pt II, 199-202, (1955).

- Movements on Major Transcurrent Faults. "Continental Drift, International Geoph. Ser.", 3, 103-134, Academic Press, New Tork and London, (1962).

- Source Wave Forms of Three Earthqualies. "Bull. Seism. Soc. Amer.", $53,893-903,(1963)$. 
Bexiofr H., Press F. and SHIT S., Excilation of the Free Oscillations of the Earth by Earthqualies. "Jour. Geoph. Res.", 66, 605-619, (1961).

Bex-MevalfeM A. and Toksoz M. N., Source-Mechanism from spectra of Long-Period Seismic Surface-Waves, 1. The Mongolian Earthquake of December 4, 19:5\%. "Jour. Geoph. Res.", 67, 1943-1955, (1962).

Benckinner H., Die A usdehnung der Bruchflache im Erdbebenherd und ihr Einfluss auf das seismische Hellenspeltrum. "Gerl. Beitr. z. Geoph.", 71, 5.26, (1962).

Buldex K. E., On Strain Energy and Strenglh in the Earth's Upper Mantle. "Trans. Amer. Geoph. Union". 34, 107-109, (1953).

-- On the Size of the Strained Region prior to an Extreme Earthquake. "Bull. Seism. Soc. Amer.", 45, 43-46, (1955).

- "An Introduction to the Theory of Seismology". 381 pp., Cambridge Univ. Press, 1963.

Byerty P. and DeNoyer J., Energy in Earlhquales as Compuled from Geodetic Observations. "Contributions in Geophysics in Honour of Beno Gutenberg ", 1, 17-35, Pergamon Press, Juondon, (1958).

I)UDA S. J., Phänomenologische Untersuchung einer Nachbebenserie aus dem. Gebiet der Aleuten-Inseln. "Freiberger Forschungshefte", C 132, 1-90. (1962).

- Strain Release in the Circum-Pacifie Belt: Chile 1960. "Jour. Geoph. Res. ", 68, 5531-5544, (1963).

I)UdA S. J. and B.tтा M., Strain Release in the Circum-Pacific Belt: Kern County 1952, Desert Hot Springs 1948, San Francisco 195\%. "Geophys. Jour. Roy. Astr. Soc. ", 7, 554-570, (1963).

Gutenberg B, and Ricirter Ch., Magnitude and Energy of Earthquakes. "Annali di Geofisica ", 9, 1-15, (1956).

Gzovsky M. V., Tectonophysics and Earlhqualie Forecasting. "Bull. Seism. Soc. Amer. ", 52, 485-505, (1962).

Lonnitz C., Eslimation Problems in Earlhquale Series. Paper presenterl at the Lpper Mantle Symposium, XIII General Assembly of IUGG, Berkeley, 15 pp., 1963.

Press F., Bex-Menamen A. and Toksöz M. N., Experimental Determination of Earthquake Faull Length and Rupture Velocity. "Jour. Geoph. Res.", 66. $3471-3485$, (1961).

Psmennikov K. W., Some Peculiarities of the Aftershocls in the Baikal Region and Mongolia (in Russian). "Geology and Geophysies", 4, $119-121,(1962)$.

Riciter C. F., "Elementary Seismology". 768 pp., W. H. Freeman and Co., San Francisco, 1958.

Riciter C. F., AlLen C. R. and Nondquist J. M., The Deserl Hot Springs Earthquakes and their Tectonic Environment. "Bull. Seism. Soc. Amer.", 48, $315-337,(1958)$.

Tocner D., Seismographic Results from the San Franciseo Earthquales of $19.5 \%$. "Calif. Dept. Nat. Resources, Division of Mines, Special Report", 57, 59-71, (1959).

T'suboi Cin.. Earthquale Energy, Earlhquake Tolume, Aftershock Area, and Strength of the Earth s Crusl. "Jour. of Phys. of the Earth" , 4, 63-66, $(1956)$.

UTsU T., A Slatistical Study on the Occurrence of Aftershocks. "Geoph. Mag. ", 30, 521-605, (1961).

UTSU T. and SEKI A., Relation belueen the Area of the Aftershock Region and the Energy of the IIain Shock. "Jour. Seism. Soc. Japan, Ser. II ", $7,233 \cdot 240,(1955)$. 